\title{
SEDIMENTOS ALBO-SANTONIANOS DA BACIA SERGIPE-ALAGOAS: AMBIENTES DE SEDIMENTAÇÃO E PERSPECTIVAS PETROLÍFERAS
}

\author{
CESAR CAINELLI*, NELSON ADÃO BABINSKI** , \\ REGINA CÉLIA RABELO DOS SANTOS** e NAMIO UESUGUI**
}

\begin{abstract}
The sedimentary sequence from Albian to Santonian in Sergipe-Alagoas Basin comprises Riachuelo and Cotinguiba formations.. It represents the initial development of an open marine sedimentation in the tectonic-sedimentary evolution of the Brazilian continental margin basins. The Albian/Cenomanian rocks (Riachuelo Formation) are composed of coarse terrigenous sediments (Angico Member) at the border of the basin, grading laterally to shales interbedded with carbonates (Taquari Member), and are topped by an essentially carbonatic sequence with development of large oolitic bats and algalic biolithites (Maruim Member), deposited in shallow marine conditions. The Turonian to Santonian rocks (Cotinguiba Formation) are composed mostly of laminated hemipelagic calcilutites, deposited at the slope of a carbonate platform which was entirely eroded. Shales from the lower part of Taquari Member have good oil-source potential but are thermally immature. The best prospects of the studied sedimentary sequence are fractured calcilutites, associated with halokynetic structures and paleo-highs basements.
\end{abstract}

INTRODUÇÃo No Brasil e no mundo, ocorre um grande empenho para se conhecer e compreender os mecanismos de formação e distribuição de calcários, visando a localização dos melhores reservatórios para acumulação de hidrocarbonetos. As rochas calcárias constituem unidades importantes nas bacias das margens continentais brasileiras, ocorrendo da Bacia de Santos à Foz do Amazonas. Notadamente na Bacia de Campos, $45 \%$ do volume do petróleo in place está em calcários albo-santonianos da Formação Macaé, contribuindo com 39\% da produção da bacia (Marroquim et al. 1984).

Na Bacia de Sergipe-Alagoas, localizada no nordeste brasileiro (Fig. 1), os calcários albo-santonianos compreendem as formações Riachuelo e Cotinguiba, formalizadas por Schaller (1969). Na evolução das bacias continentais marginais brasileiras esses calcários situam-se no estágio de mar aberto com o progressivo afastamento das placas sulamericana e africana (Asmus \& Baisch 1983) (Fig. 2).

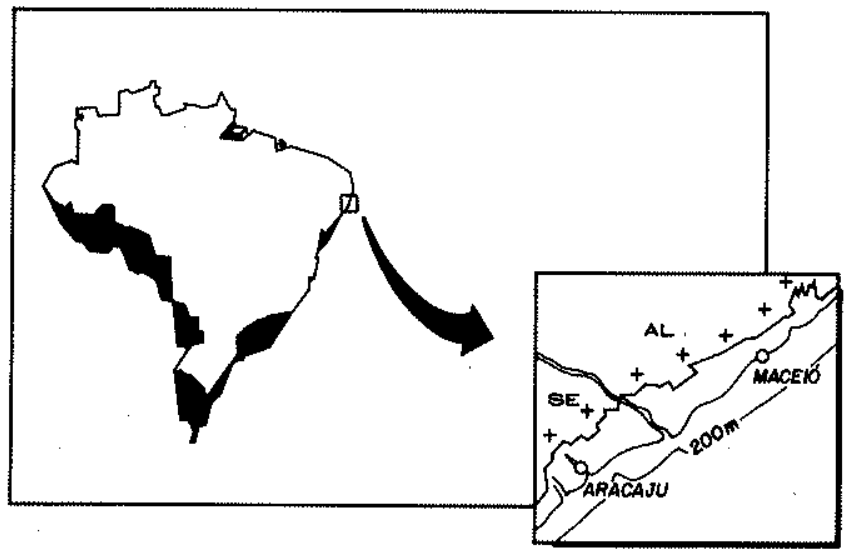

Figura 1 - Mapa de localização

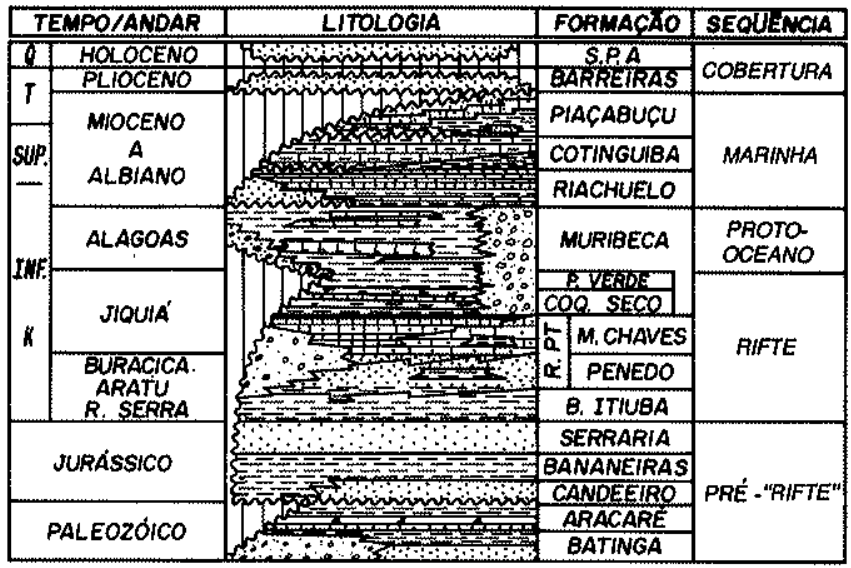

Figura 2 - Quadro estratigráfico generalizado da Bacia de Sergipe-Alagoas (Adaptado de Schaller et al. 1980)

DEFINIÇÃO CRONOLITOESTRATIGRAFICA A seção sedimentar albo-santoniana (Fig. 3) foi subdividida em três unidades cronoestratigráficas menores, baseadas em datações paleontológicas, correlação de 200 poços e dados sísmicos visando uma melhor compreensão crono e litoes. tratigráfica:

Seção A Constitui a unidade basal assentando concordante ou discordantemente sobre a Formação Muribeca (Andar Alagoas). Depositada no Andar Albiano, compreende os membros Angico e Taquari interdigitados da Formação Riachuelo.

MEMBRO ANGICO: É formado por conglomerado com seixos e matacoses de quartzito, gnaisse e arenito. Grada

* Petróleo Brasileiro S.A. (Petrobrás), Departamento de Exploração. Av. Chile, 65, CEP 20035, Rio de Janeiro, RJ, Brasil

* Centro de Pesquisas da Petrobrás (Cenpes), Divisão de Exploração. Cidade Universitária, Quadra 7, Ilha do Fundão, CEP 21910, Rio de Janeiro, RJ, Brasil 
lateralmente para arenitos conglomeráticos e quartzofeldspáticos.

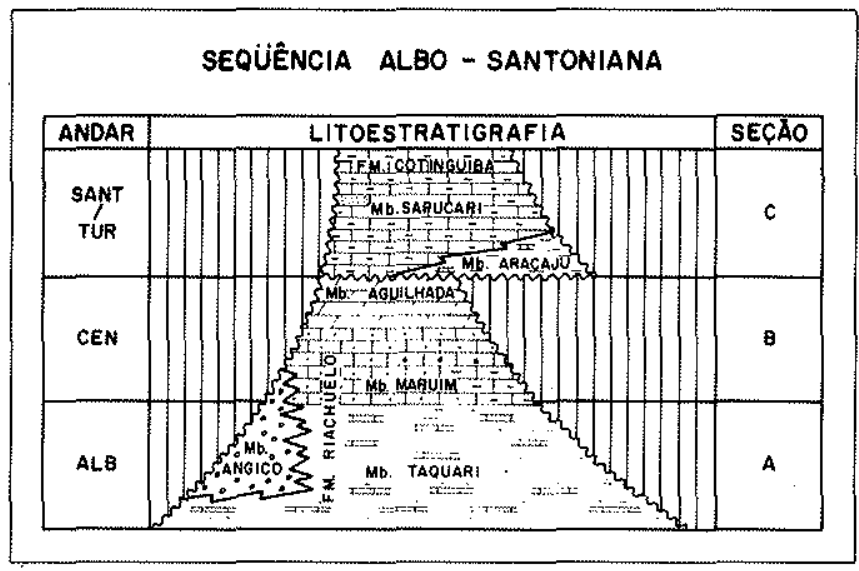

Figura 3 - Divisão da Seqüência Albo-Santoniana

MEMBRO TAQUARI: $\mathrm{E}$ composto por finas intercalações de folhelhos calcíferos e calcilutitos laminados com foraminíferos planctônicos e calcisferas, além de corpos locais de biolititos algálicos.

Seção B Depositada no Andar Cenomaniano, seu con. tato inferior é concordante com a Seção A e definido por uma mudança litológica e ambiental marcante. Abrange os membros Angico, Maruim e Aguilhada da Formação Riachuelo.

MEMBRO MARUIM: Constitui-se de calcarenitos oolíticos algálicos, geralmente com cimento espático em mosaico. São comuns biolititos de algas azuis-verdes e vermelhas, e bioacumulações locais de gastrópodes.

MEMBRO AGUILHADA: $\overrightarrow{\mathrm{E}}$ formado por dolomitos, onde localmente se observam relíquias de oólitos. Trata-se de litologias dolomitizadas do Membro Maruim.

Seção C Seu contato inferior é marcado por uma dis. cordância angular e erosiva bem evidenciada nos aflora. mentos e seções sísmicas próximas a Aracaju. Marca a passagem de pacotes cronológicos distintos. $O$ contato superior é discordante com as formações. Piaçabuçu e Barreiras. Foi sedimentada durante os andares Turoniano a Santoniano através dos membros Aracaju e Sapucari da Formação Cotinguiba.

MEMBRO ARACAJU: Compõe-se de folhelhos e siltitos intercalados com calcilutitos e margas.

MEMBRO SAPUCARI: É formado por calcilutitos laminados e finamente estratificados, e calcilutitos maciços, nodulares a brechóides. São micritos com biota de foramini. feros planctônicos, radiolários e calcisferas.

OCORRENCIA E ESPESSURA A principal e a mais importante constatação que se faz ao se superporem os vários mapas isópacos ao mapa estrutural do embasamento, é o controle exercido pela tectonica na espessura e faciologia das seções. Poços perfurados no bloco baixo de falhas sintectônicas, estabelecidas em linhas de fraqueza preexis. tentes do embasamento, mostram grandes espessuras sedimentares: Baixo da Itha das Flores, Japaratuba, Divina Pastora etc. (Figs. 4 e 5). Por essa razão, nos altos estruturais (por exemplo Aracaju) os baixos valores de isópacas devem-se à menor deposição aliada à maior erosão que atua até hoje nos locais onde a seqüência aflora. Em Alagoas, a mesma está praticamente ausente por não deposição, pois esta porção da bacia já se manifestava como área positiva no final do Andar Alagoas. As pequenas espessuras na porção marinha devem-se à Discordância Erosiva Pré-Calumbi e acunhamento deposicional. Assim, o fácies distal dos calcários de água rasa remanescentes da Seção B (Membro Maruim) foram erodidos pelos cânions escavados pela Discordância Pré-Calumbi corroborada pela Pré-Cotinguiba que separa as seções B e C (Fig. 7). A Seção A, por ser a basal, foi menos atingida pela erosão, apresentando a maior extensão em área (Fig. 6).

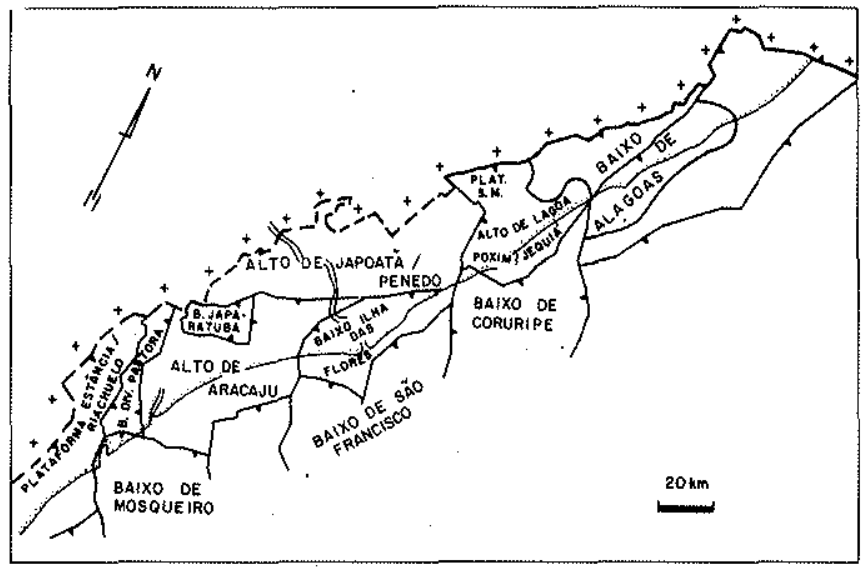

Figura 4 - Mapa com as principais feições tectônicas da Bacia de Sergipe-Alagoas

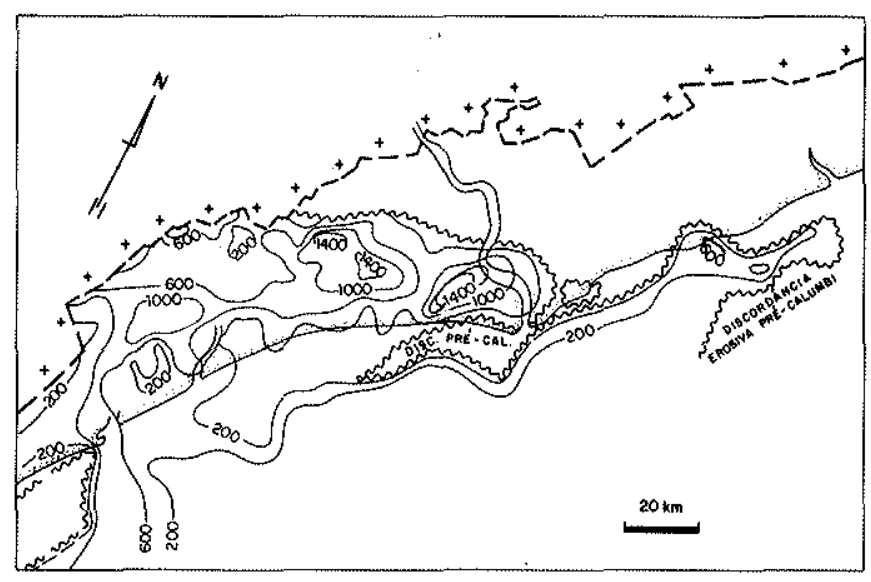

Figura 5 - Mapa isópaco remanescente da Seqüência Albo-Santoniana

\section{EVOLUÇÃO TECTONO-SEDIMENTAR E AMBIENTE} DE SEDIMENTAÇÃo Seção A Com o afastamento progressivo das placas sul-americana e africana, e o conse. qüente resfriamento e subsidência, tem início, no Andar Albiano, o estágio oceânico da bacia, com o mar ultrapassando as antigas barreiras e restrições do "proto-Oceano Alagoas". Este passo na evolução da bacia é acompanhado por reativação de antigas falhas onde nas bordas da bacia se depositavam conglomerados e arenitos, intercalados a fothelhos e calcários, evidenciando um influxo cíclico de terrígenos grossos provenientes de fonte periodicamente rejuvenescidas (Fig. 9). Estes terrígenos entravam num corpo 


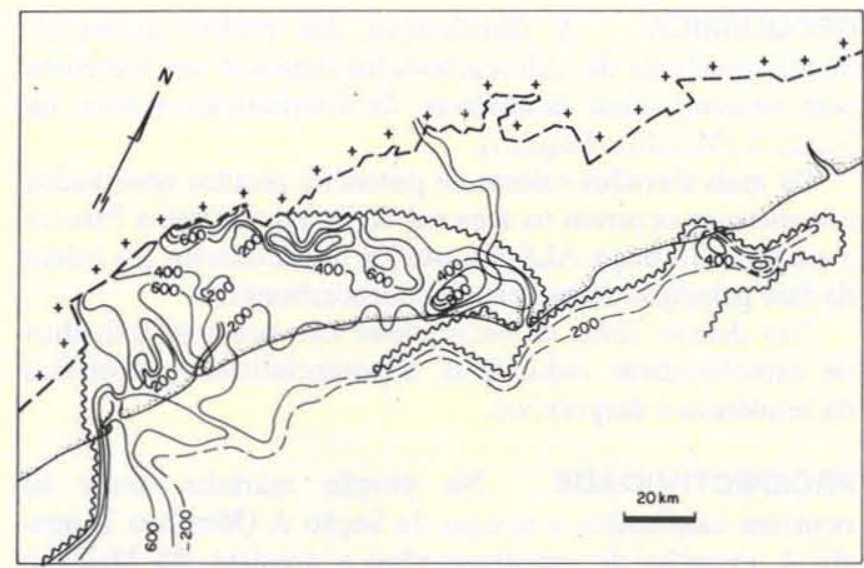

Figura 6 - Mapa isópaco remanescente da Seção $A$

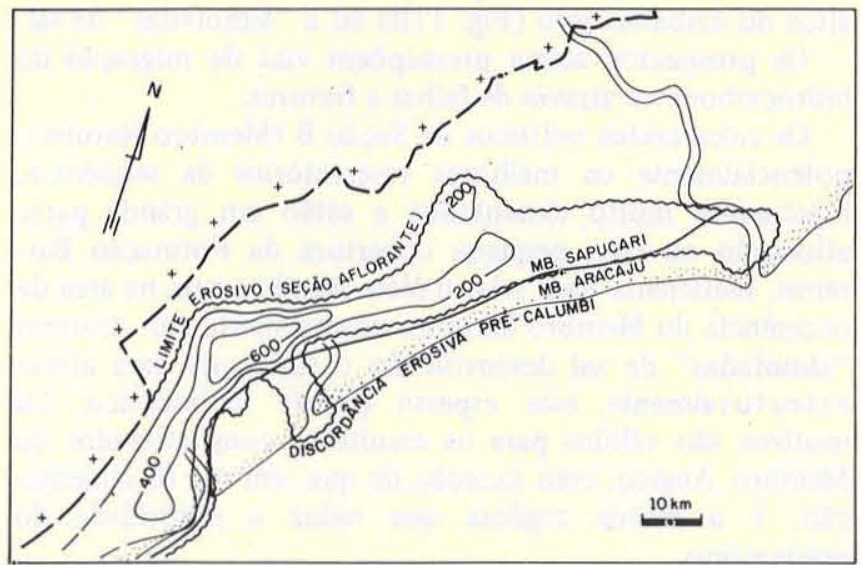

Figura 8 - Mapa isópaco remanescente da Seção C

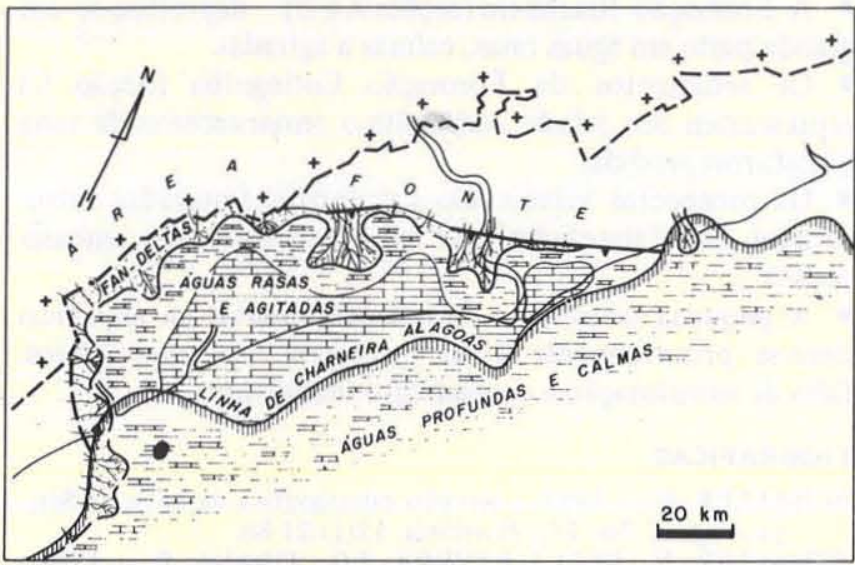

Figura 10 - Mapa paleoambiental da Seção B (membros Angico, Maruim e Aguilhada inierdigitados)

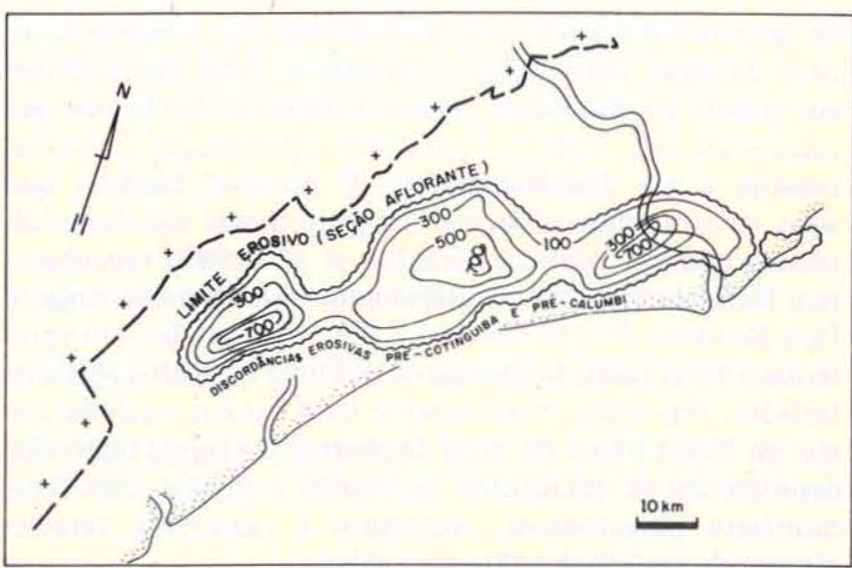

Figura 7 - Mapa isópaco remanescente da Seção B

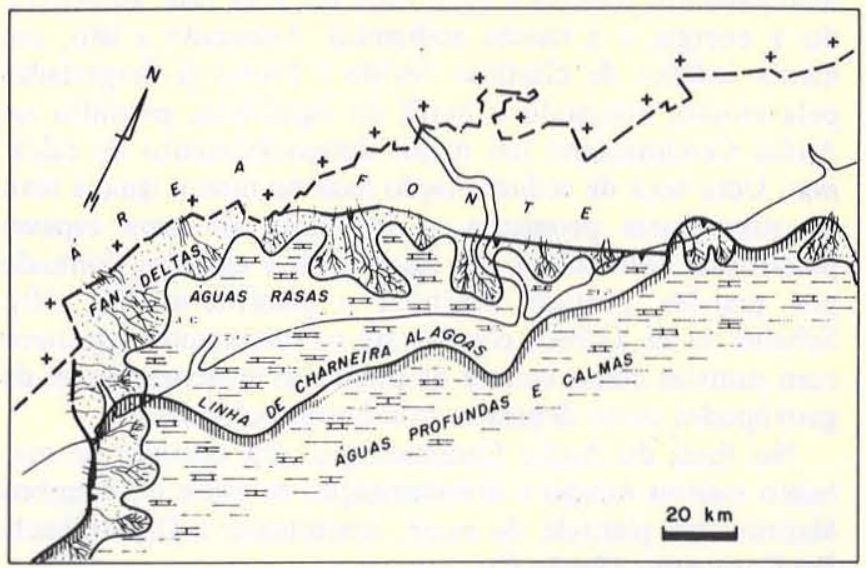

Figura 9 - Mapa paleoambiental da Seção A (membros Angico e Taquari interdigitados)

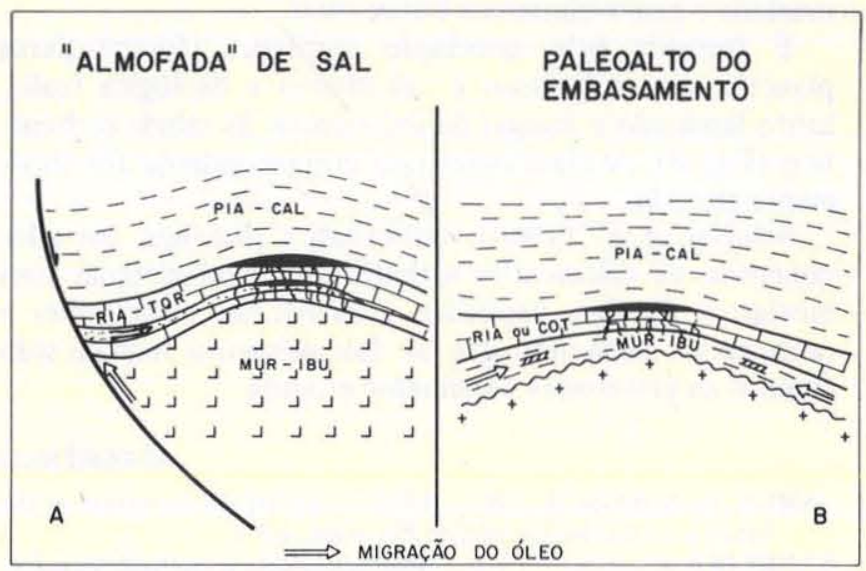

Figura 11 - Prospectos mais propicios para a acumulação de hidrocarbonetos 
de água relativamente raso, intercalados com oólitos e biolititos de algas azuis-verdes e vermelhas. Estas não viveriam em grande profundidade, pois o influxo de terrígenos que caracteriza esta seção não permitiria a penetração da luz necessária a seu desenvolvimento. É provável também que algas vivendo num substrato terrígeno móvel não desenvol* vessem grandes colônias. Schaller et al. (1980) reconheceram fácies de turbidez em afloramentos do Membro Angico. Para Bandeira Jr. (1978), se a topografia do substrato apresentava áreas rasas, formavam-se oólitos e biolititos algálicos isolados. Nas águas relativamente mais fundas e calmas, como no bloco baixo da linha de charneira Alagoas reativada, depositavam-se calcilutitos laminados e margas com foraminíferos planctônicos, radiolários e calcisferas, característicos de plataforma externa e talude.

Em resumo, teríamos fanglomerados nas bordas ativas assoreando intermitentemente uma bacia rasa, onde se desenvolviam biolititos algálicos e oólitos nas porções mais elevadas e calcilutitos a margas nas partes mais profundas e distais.

Seção B A medida que à sedimentação prosseguia, o assoreamento tornava a bacia cada vez mais rasa, aumentando a energia e a tensão ambiental. Associado a isto, um menor influxo de clásticos devido a fontes já desgastadas pela erosão, atingindo o perfil do equilíbrio, permitiu no Andar Cenomaniano um maior desenvolvimento de calcários. Uma taxa de sedimentação mais ou menos igual à taxa de subsidência propiciou a deposição de uma espessa plataforma carbonática em águas rasas e agitadas, formada por grandes pacotes oolíticos e pisolíticos (Fig. 10). Schaller et al. (1980) consideram os calcarenitos espáticos com rudistas como bancos de praia e as bioacumulações de gastrópodes como depósitos-interbarras oolíticos.

No final do Andar Cenomaniano, um período de mar baixo causou erosão e dolomitização de parte do Membro Maruim em planície de maré, acarretanto a Discordância Pré-Cotinguiba (Seção C).

Em síntese, teríamos fanglomerados de borda ativa menos expressivos que na Seção $A$, com grande desenvolvimento de barras oolíticas associadas a biolititos algálicos numa bacia com águas rasas e agitadas.

Seção C No Andar Turoniano, a bacia sofreu uma transgressão que ultrapassou os limites da bacia albo-cenomaniana e provavelmente a borda atual.

E formada pela associação faunística (foraminíferos planctônicos, radiolários e calcisferas) e litológica (calcilutito laminado e marga) de sedimentos de talude carbonático (Fig. 8). A plataforma rasa correspondente foi totalmente erodida.

Schaller et al. (1980) verificaram a presença, em afloramentos, de calcarenitos turbidíticos e olistostromas com bioclastos de algas vermelhas coralináceas, pelecípodes e raros corais, sugerindo que os dois primeiros tenham sido comuns na plataforma atualmente erodida.
GEOQUIMICA A distribuição das rochas potencialmente geradoras de hidrocarbonetos limita-se aos folhelhos com características radioativas, de distribuição restrita, da Seção A (Membro Taquari).

Os mais elevados valores de potencial gerador observados nos mesmos ocorrem na área sul do Baixo de Divina Pastora e na área do poço ALS-30, porém se encontram nọ início da fase principal de geração de hidrocarbonetos.

Nas demais áreas da bacia, onde não ocorrem folhelhos de características radioativas, a potencialidade petrolífera da seqüência é desprezível.

PROSPECTIVIDADE Na porção marinha, onde só ocorrem calcilutitos e margas da Seção A (Membro Taqua* ri), à exceção de conglomerados e arenitos do Membro Angico no Baixo de Mosqueiro, as maiores possibilidades de acumulação de hidrocarbonetos estão em calcilutitos fratu* rados, estruturados pela movimentação halocinética subjacente (Fig. 11A).

$\mathrm{Na}$ porção terrestre, as melhores chances estão em calcilutitos fraturados da Seção A (Membro Taquari) e da Seção C (Formação Cotinguiba), quando prôximos a paleoaltos do embasamento (Fig. 11B) ou a "almofadas" de sal.

Os prospectos acima pressupõem vias de migração de hidrocarbonetos através de falhas e fraturas.

Os calcarenitos oolíticos da Seção B (Membro Maruim), potencialmente os melhores reservatórios da sequêencia, mostram-se muito cimentados e estão em grande parte aflorando ou com pequena cobertura da Formação Barreiras, ineficiente para selar o óleo. Aliado a isto, na área de - ocorrência do Membro Maruim, normalmente não ocorrem "almofadas" de sal desenvolvidas o suficiente para afetar estruturalmente este espesso pacote carbonático. Os motivos são válidos para os arenitos e conglomerados do Membro Angico, com exceção de que, em vez da cimentação, é a matriz argilosa que reduz a porosidade do reservatório.

Assim, devido em grande parte a esses fatores, a ocorrência de hidrocarbonetos nesta seqüência é reduzida, apesar do grande número de poços que a atravessam.

\section{CONCLUSÕES}

- A divisão cronoestratigráfica em três seções revelou-se eficaz para uma melhor compreensão da seqüência.

- A Formação Riachuelo (seções Ae B). depositou-se em grande parte em águas rasas, calmas a agitadas.

- Os sedimentos da Formação Cotinguiba (Seção C) representam um talude carbonático remanescente de uma plataforma erodida.

- Os prospectos viáveis são calcilutitos fraturados estruturados por "almofadas" de sal e paleoaltos de embasamento.

- A pequena ocorrência de hidrocarbonetos na seqüència deve-se provavelmente à má qualidade dos reservatórios, falta de estruturação e capeamento ineficiente.

\section{REFERENNCIAS BIBLIOGRÁFICAS}

ASMUS, H. \& BAISCH, P.R. - 1983 - Geological evolution of the brazilian continental margin. Episodes, 4:3-9.

BANDEIRA Jr., A.N. - 1978 - Sedimentologia e microfácies calcárias das Formaçöes Riachuelo e Cotinguiba da Bacia SergipeAlagoas. Rio de Janeiro, Petrobrás-Cenpes. (Rel. Int.).

MARROQUIM, M.; TIGRE, C.A.; LUCCHESI, C.F. - 1984 - Bacia de Campos: resultados e perspectivas. In: CONGR. BRAS. GEOL.,33, Rio de Janeiro, 1984. Anais... Rio de Janeiro, SBG. v. 3 , p. $1366+1370$.
SCHALLER, H. - 1969 - Revisão estratigráfica da Bacia de Sergipe-Alagoas. Bol. Téc. Petrobrás, 12(1):21-86.

SCHALLER, H.; DELLA FAVERA, J.C.; TIBANA, P. - 1980 -Roteiro Geológico da Bacia de Sergipe-Alagoas. Rio de Janeiro, Petrobrás-Cenpes. (Rel. Int.). 